\title{
Risk factors for episiotomy: a case-control study
}

\author{
Giordana Campos Braga ${ }^{1 *}$, Suelem Taís Pereira Clementino ${ }^{1}$, Patrícia Ferreira Neves da Luz ${ }^{1}$, Adriana Scavuzzi ${ }^{2}$, Carlos \\ Noronha Neto ${ }^{2}$, Melania Maria Ramos Amorim² \\ ${ }^{1}$ Medical Doctor of Obstetrics and Gynecology, Postgraduate Program on Maternal and Child Health, Professor Fernando Figueira Mother and Child Institute (IMIP), Recife, PE, Brazil \\ 2Professor of Obstetrics and Gynecology, Postgraduate Program on Maternal and Child Health, Professor Fernando Figueira Mother and Child Institute (IMIP), Recife, PE, Brazil
}

Study conducted at the Professor Fernando Figueira Integral Medicine Institute (IMIP), Recife, PE, Brazil

Article received: $4 / 3 / 2013$ Accepted for publication: $1 / 31 / 2014$

*Correspondence: Address: Rua José Saretta, 155, Nova Aliança Ribeirão Preto, SP - Brazi Postal Code: $14026-593$ Phone: +55 16 9233-0662 giordanacb@yahoo.com.br http://dx.doi.org/10.1590/1806-9282.60.05.015 Conflict of interest: none

\section{SUMMARY}

Objective: obtaining information on the factors associated with episiotomy will be useful in sensitizing professionals to the need to minimize its incidence. Therefore, the objective of this study was to evaluate risk factors for episiotomy in pregnant women who had undergone vaginal delivery at a university maternity hospital in northeastern Brazil.

Methods: a case-control study was conducted with pregnant women submitted to episiotomy (cases) and pregnant women not submitted to episiotomy (controls) between March 2009 and July 2010 at the Professor Fernando Figueira Integral Medicine Institute (IMIP) in Recife, Brazil, in a ratio of 1 case to 2 controls. The study variables consisted of: whether episiotomy was performed, demographic, obstetric and fetal characteristics (primiparity, analgesia, instrumental delivery, fetal distress, etc.), external factors (day and time of delivery, professional attending delivery) and factors directly related to delivery. Odds ratios (OR) and 95\% confidence intervals $(95 \% \mathrm{CI})$ were calculated. Multivariate analysis was performed to determine the adjusted risk of episiotomy.

Results: a total of 522 women (173 cases and 349 controls) were included. It was found that deliveries with episiotomy were more likely to have been attended by staff physicians (OR $=1.88 ; 95 \%$ CI: 1.01 - 3.48), to have required forceps $(\mathrm{OR}=12.31 ; 95 \% \mathrm{CI}: 4.9-30.1)$ and to have occurred in primiparas $(\mathrm{OR}=4.24$; 95\%CI: $2.61-6.89$ ). The likelihood of a nurse having attended the delivery with episiotomy was significantly lower ( $\mathrm{OR}=0.29 ; 95 \% \mathrm{CI}$ : 0.16 - 0.55 ).

Conclusion: episiotomy was found to be strongly associated with deliveries attended by staff physicians, with primiparity, and with instrumental delivery, and was less common in deliveries attended by nurses.

Keywords: episiotomy, natural childbirth, risk factors, perineum/injuries, case-control studies.

\section{INTRODUCTION}

Episiotomy, which consists in an incision on the perineum to widen the birth canal, was for a long time the principal procedure performed during childbirth. With the objective of protecting the pelvic floor and preventing fetal trauma during birth, its routine use was widely accepted in the past, principally in primipara (woman in her first labor and delivery). ${ }^{1}$

Nevertheless, a systematic review available in the Cochrane Library showed that episiotomy is not only a pro- cedure that should not be performed routinely but also it is both unnecessary and possibly harmful. That Cochrane review included eight randomized clinical trials, involving more than 5,000 women. Routine episiotomy was found to be associated with greater blood loss during childbirth, perineal pain, an increased risk of severe perineal laceration, a greater risk of scarring complications and a greater need for stitches, with no clearly demonstrated benefit to the mother and/or infant. On the contrary, the authors 
concluded that the benefits of selective episiotomy (indicated under special circumstances) are much greater than those found with routine episiotomy. ${ }^{2}$

Although the occasions in which a selective episiotomy should be performed are yet to be defined, publication of the results of controlled clinical trials and of the Cochrane systematic review has led to a significant decline in the rates of this procedure. ${ }^{3,4}$ Since 1996, the World Health Organization has stipulated an episiotomy rate of around $10 \%$ as being acceptable, ${ }^{5,6}$ although the procedure continues to be performed routinely by a variety of professionals in various countries. ${ }^{7}$

Evidence suggests a need for continued medical education and programs aimed at sensitizing the professionals involved in attending childbirth in order to reduce the use of this procedure. ${ }^{3,7,8}$ There is also a need to document the factors associated with the use of episiotomy and to monitor the progressive reduction in its use following introduction of a policy adopted to restrict its practice.

Therefore, the present study was conducted with the objective of describing the frequency of episiotomy in a university maternity hospital in the Northeast of Brazil and identifying the principal factors associated with the procedure.

\section{Methods}

An analytical, observational, case-control study was conducted with women who had undergone vaginal delivery at the (IMIP) in Recife, Pernambuco, Brazil. The study was conducted between March 2009 and July 2010 following approval by the institution's internal review board (reference\#1284-08). All the women voluntarily agreed to participate in the study and signed an informed consent form.

Sample size was calculated using the Statcalc module of the Epi-Info program, version 3.5.3. (Atlanta, GA, USA). Considering a frequency of forceps delivery without episiotomy of $1 \%$ and an odds ratio (OR) of $7.0{ }^{9}$ for a case to control ratio of 1:2,173 cases and 349 controls would be required to show a difference, making a total of 522 women.

A consecutive convenience sample was obtained, consisting of all the women who fulfilled the eligibility criteria and who were in the maternity ward when the investigators made their visits every other day, during the day shift. The women were interviewed immediately following delivery, prior to their release from hospital. The inclusion criterion was having had an assisted vaginal de- livery at IMIP. Women who had been submitted to episiotomy were considered cases, while those who had not undergone episiotomy were admitted as controls. Women unable to give their informed consent (those in a coma, unconscious or mentally retarded) and who did not have an accompanying person with them who could consent to their participation in the study on their behalf were excluded from the study.

The dependent variable was having undergone episiotomy in any form (mediolateral or midline) and the independent variables were: a) maternal variables: age (years), parity, ethnicity (brown, black, white, yellow or indigenous), nutritional status evaluated according to body mass index (BMI), sociodemographic characteristics (place of origin and years of schooling); b) complications of pregnancy (diseases inherent to pregnancy or occurring during pregnancy), gestational age at delivery (weeks), previous Cesarean section, previous episiotomy; c) fetal characteristics: fetal presentation and fetal position during labor; d) external factors: the work shift, the professional attending delivery and the time of delivery; e) direct factors (related to delivery): induction or conduction of delivery, position at delivery (supine or other), type of delivery (spontaneous or instrumental), duration of expulsive phase, use of analgesia during delivery, presence of non-reassuring fetal heart rate, shoulder dystocia and fetal macrosomia.

The data were collected on standardized forms precoded for computer data entry. The statistical analysis was performed using the publicly available Epi-Info software program, version 7 (Atlanta, GA, USA). Measures of central tendency and dispersion and frequency distribution were used to describe the baseline characteristics. To determine the association between the dependent variable (episiotomy) and the independent variables (predictors), the chi-square test of association and Fisher's exact test were used, as appropriate, at a 5\% significance level. The odds ratios (OR) and $95 \%$ confidence intervals $(95 \% \mathrm{CI})$ were calculated. Multivariate analysis was carried out following a model of hierarchical multiple logistic regression ${ }^{10}$ to determine the adjusted risk of episiotomy.

\section{Results}

During the study period, 2,563 vaginal deliveries were performed in the institute, with a frequency of episiotomy at around $10 \%$ (259 cases). Of these, 542 women were approached and 522 women agreed to participate in the study: 173 cases and 349 controls (Figure 1). 


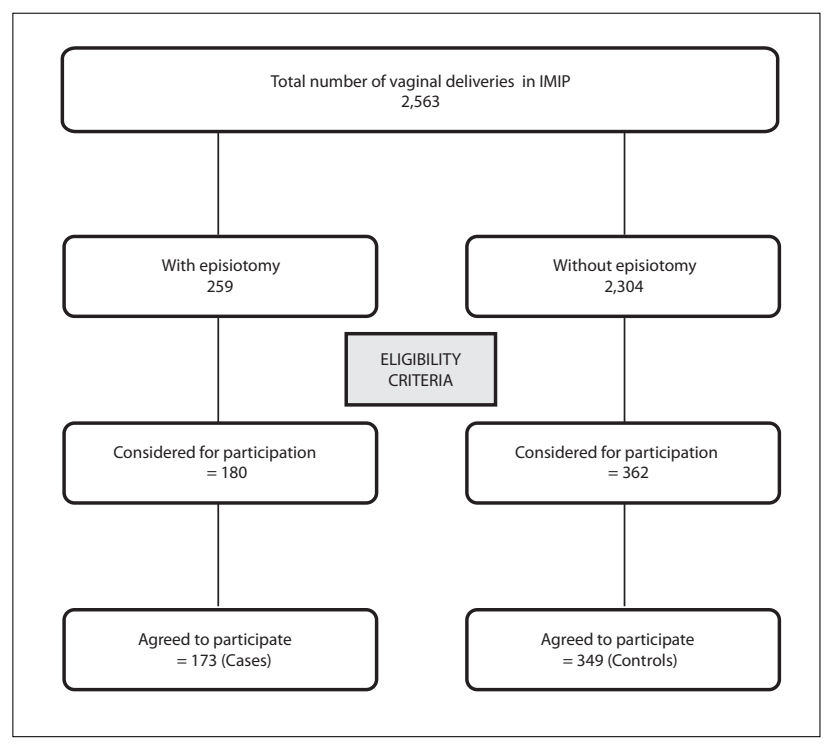

FIGURE 1 Flow chart of the study.

The age of the women ranged from 13 to 44 years, with a mean of around 24 years of age. The median number of previous pregnancies and deliveries was 1 , with a percentage of primiparas of $61.7 \%$. The majority of the women $(72 \%)$ had at least eight years of schooling and $45 \%$ came from the city of Recife. Mean gestational age at delivery was 37.6 weeks, with $29.5 \%$ of prematurity $(<37$ weeks). Complications had occurred during pregnancy in around $52 \%$ of the participants, with a frequency of hypertensive syndromes of approximately $35 \%$. Induction of labor with oxytocin was required in $55 \%$ of the women and $9.4 \%$ were submitted to instrumental delivery with the use of forceps (Table 1 ).

\begin{tabular}{|c|c|c|}
\hline Characteristic & & \\
\hline Age (range. mean $\pm \mathrm{SD})$ & $13-44$ & $23.9 \pm 6$ \\
\hline Previous pregnancies (range. median) & $1-15$ & 1 \\
\hline Previous deliveries (range. median) & $1-12$ & 1 \\
\hline Primiparas (n. \%) & 322 & 61.7 \\
\hline \multicolumn{3}{|l|}{ Schooling } \\
\hline$<8$ years of schooling & 148 & 28.4 \\
\hline$\geq 8$ years of schooling & 373 & 71.6 \\
\hline \multicolumn{3}{|l|}{ Place of origin } \\
\hline Recife & 234 & $44.9 \%$ \\
\hline Other towns & 288 & 55.2 \\
\hline Gestational age at delivery (range. mean \pm SD) & $23-42$ & $37.6 \pm 2.9$ \\
\hline Prematurity (n. \%) & 154 & 29.5 \\
\hline Complications in pregnancy & 272 & $52.1 \%$ \\
\hline Hypertensive syndromes & 182 & $34.9 \%$ \\
\hline Delivery induced (n. \%) & 286 & $54.8 \%$ \\
\hline Instrumental delivery (n. \%) & 49 & $9.4 \%$ \\
\hline
\end{tabular}

\section{TABLE 2 Maternal and fetal factors associated with the use of episiotomy}

\begin{tabular}{|c|c|c|c|c|c|c|c|}
\hline \multirow{3}{*}{ Associated factors } & \multicolumn{4}{|c|}{ Episiotomy } & \multirow{3}{*}{ OR } & \multirow{3}{*}{$95 \% \mathrm{Cl}$} & \multirow{3}{*}{ p-value } \\
\hline & \multicolumn{2}{|c|}{ Yes $=173$} & \multicolumn{2}{|c|}{ No $=349$} & & & \\
\hline & $\mathbf{n}$ & $\%$ & n & $\%$ & & & \\
\hline Maternal age $<20$ years & 64 & 37 & 63 & 20.9 & 2.22 & $1.48-3.32$ & 0.00009 \\
\hline Primiparity & 144 & 83.2 & 178 & 51 & 3.08 & $2.16-4.41$ & 0.0000000 \\
\hline Black skin color & 17 & 9.8 & 53 & 15.2 & 0.61 & $0.34-1.09$ & 0.09 \\
\hline Overweight/obese & 41 & 23.7 & 110 & 31.5 & 0.67 & $0.44-1.02$ & 0.06 \\
\hline$<8$ years of schooling & 38 & 22 & 110 & 31.5 & 0.61 & $0.4-0.94$ & 0.02 \\
\hline Lives in Recife & 70 & 40.5 & 164 & 59.5 & 0.77 & $0.65-1.07$ & 0.16 \\
\hline Prematurity & 51 & 29.5 & 122 & 47 & 1 & $0.76-1.3$ & 0.99 \\
\hline Complications during pregnancy & 98 & 56.6 & 174 & 49.9 & 1.31 & $0.94-1.54$ & 0.14 \\
\hline Previous cesarean section & 9 & 5.2 & 20 & 5.7 & 0.9 & $0.4-2.03$ & 0.8 \\
\hline Previous episiotomy & 16 & 9.2 & 97 & 27.8 & 0.26 & $0.15-0.47$ & 0.000002 \\
\hline Pelvic presentation & 4 & 2.3 & 2 & 0.6 & 4.11 & $0.74-22.64$ & $0.19 *$ \\
\hline Occipito-posterior position & 22 & 28.6 & 41 & 36.9 & 0.68 & $0.36-1.28$ & 0.23 \\
\hline
\end{tabular}

95\% Cl: 95\% confidence interval; OR: Odds Ratio.

* Fisher's exact test (two-tailed). 
Analysis of the maternal risk factors showed that the women submitted to episiotomy were more likely to be adolescents $(\mathrm{OR}=2.22 ; 95 \% \mathrm{CI}: 1.48-3.32)$ and primiparas $(\mathrm{OR}=3.08$; 95\%CI: $2.16-4.41)$ and less likely to have fewer than eight years of schooling $(\mathrm{OR}=0.61 ; 95 \% \mathrm{CI}$ : 0.40 - 0.94) or a history of having had a previous episiotomy $(\mathrm{OR}=0.26$; 95\%CI: $0.15-0.47)$. There was no association between episiotomy and the presence of complications during pregnancy $(\mathrm{p}=0.14)$, overweight/obesity $(\mathrm{p}=0.06)$, being black $(p=0.09)$, coming from Recife $(p=0.16)$, prematurity $(p=0.99)$ or having had a previous Cesarean section $(p=0.80)$. In relation to fetal risk factors, no association was found between episiotomy and pelvic presentation $(\mathrm{p}=0.19)$ or occiput posterior fetal position during labor $(\mathrm{p}=0.23)($ Table 2$)$.

With respect to the factors directly related to care at delivery, the women submitted to episiotomy were more likely to have had labor induced with oxytocin $(\mathrm{OR}=1.92$; $95 \%$ CI: $1.31-2.79)$, an instrumental delivery $(\mathrm{OR}=18.91$; 95\%CI: 7.86 - 45.48), a prolonged expulsive phase (12\% versus $0 \%$, OR not calculated, $\mathrm{p}<0.000001)$, analgesia during labor $(\mathrm{OR}=3.0 ; 95 \% \mathrm{CI}$ : $1.77-5.08)$ and a diagnosis of non-reassuring fetal heart rate $(\mathrm{OR}=3.4 ; 95 \% \mathrm{CI}: 1.82$ - 6.37). There was no association between episiotomy and delivery in the supine position $(\mathrm{p}=0.05)$ or fetal macrosomia $(\mathrm{p}=0.52)($ Table 3$)$.

Regarding the external factors evaluated, the women submitted to episiotomy were three times more likely to have been attended by a staff physician $(\mathrm{OR}=3.36$; 95\% CI: $1.97-5.72)$. On the other hand, delivery attended by nurses or resident nurses was found to constitute a protective factor against episiotomy $(\mathrm{OR}=$ 0.19; 95\% CI: $0.10-0.35)$. There was no association between episiotomy and the day of the week or work shift (Table 3).

When multivariate analysis was performed using a hierarchical logistic regression model, the factors that remained significantly associated with a greater risk of episiotomy were primiparity ( $\mathrm{OR}=4.24 ; 95 \% \mathrm{CI}: 2.61-6.89)$, instrumental delivery $(\mathrm{OR}=12.31 ; 95 \% \mathrm{CI}$ : $4.9-30.81)$ and delivery attended by a staff physician $(\mathrm{OR}=1.88$; $95 \% \mathrm{CI}: 1.01-3.48)$, whereas a reduction in the risk was found when delivery was attended by a nurse $(\mathrm{OR}=0.24$; 95\%CI: 0.16 - 0.55) (Table 4).

TABLE 3 Intrapartum and external factors associated with the use of episiotomy

\begin{tabular}{|c|c|c|c|c|c|c|c|}
\hline \multirow{3}{*}{ Associated factors } & \multicolumn{4}{|c|}{ Episiotomy } & \multirow{3}{*}{ OR } & \multirow{3}{*}{$95 \% \mathrm{Cl}$} & \multirow{3}{*}{ p-value } \\
\hline & \multicolumn{2}{|c|}{ Yes $=173$} & \multicolumn{2}{|c|}{$\mathrm{No}=349$} & & & \\
\hline & $\mathbf{n}$ & $\%$ & $\mathbf{n}$ & $\%$ & & & \\
\hline Induction of delivery & 113 & 65.3 & 173 & 49.6 & 1.92 & $1.31-2.79$ & 0.0007 \\
\hline Supine position & 81 & 46.8 & 195 & 55.9 & 0.69 & $0.48-1$ & 0.05 \\
\hline Instrumental delivery & 43 & 24.9 & 6 & 1.7 & 18.91 & $7.86-45.48$ & 0.00000000 \\
\hline Prolonged expulsive phase & 22 & 12 & 0 & 0 & $\mathrm{NE}^{*}$ & $N E^{*}$ & 0.00000000 \\
\hline Analgesia at delivery & 37 & 21.4 & 29 & 8.3 & 3 & $1.77-5.08$ & 0.00002 \\
\hline Fetal distress & 27 & 15.6 & 18 & 5.2 & 3.4 & $1.82-6.37$ & 0.00006 \\
\hline Fetal macrosomia & 5 & 2.9 & 9 & 2.6 & 1.12 & $0.37-3.41$ & $>0.999999 *$ \\
\hline Sunday shift & 33 & 19.1 & 46 & 13.2 & 1.32 & $0.98-1.77$ & 0.08 \\
\hline Tuesday shift & 18 & 10.4 & 44 & 12.6 & 0.81 & $0.45-1.44$ & 0.23 \\
\hline Night shift & 88 & 50.9 & 175 & 50.1 & 1.03 & $0.71-1.48$ & 0.88 \\
\hline Delivery attended by medical staff & 38 & 22 & 27 & 7.7 & 3.36 & $1.97-5.72$ & 0.000005 \\
\hline Delivery attended by nurse or resident nurse & 14 & 8.1 & 109 & 31.2 & 0.19 & $0.1-0.35$ & 0.0000000 \\
\hline
\end{tabular}

95\%Cl: 95\% confidence interval; OR: Odds Ratio; $\mathrm{NE}=$ Not estimated.

* Fisher's exact test. 
TABLE 4 Multivariate analysis of the principal factors associated with episiotomy

\begin{tabular}{l|l|l|l|l|l}
\hline Variable & Odds Ratio & $\mathbf{9 5 \% C l}$ & Coefficient & Standard Error & $\mathbf{p}$-value \\
\hline Delivery attended by nurse & 0.29 & $0.16-0.55$ & -1.2248 & 0.32 & 0.0001 \\
\hline Instrumental delivery & 12.31 & $4.9-30.81$ & 2.5101 & 0.47 & 0.0000 \\
\hline Primiparity & 4.24 & $2.61-6.89$ & 1.4441 & 0.25 & 0.0000 \\
\hline Delivery attended by staff physician & 1.88 & $1.01-3.48$ & 0.6292 & 0.31 & 0.0457 \\
\hline Constant & & & -1.7816 & 0.22 & 0.0000 \\
\hline
\end{tabular}

\section{Discussion}

The results of the present study suggest that the most important factors associated with episiotomy at IMIP are: primiparity, delivery attended by a staff physician and the use of forceps. In the case of women in whom episiotomy was not performed, their delivery was more likely to have been attended by nurses.

There was a 4-fold greater likelihood of episiotomy having been performed in primiparas. These results are in agreement with findings reported in the literature. One study conducted in the United States including 8,647 patients showed a frequency of episiotomy of $50 \%$ in primiparas compared to $23 \%$ in secundiparas and multiparas, a difference that was statistically significant. ${ }^{11}$ Nevertheless, these data may reflect a more liberal practice of episiotomy in primiparas rather than any real need for the procedure in this group of women.

A clinical trial conducted in Venezuela showed no advantage in the routine use of episiotomy in primiparas ${ }^{12}$ and the subgroup analysis in a Cochrane systematic review also did not favor the practice of episiotomy in primiparous women ${ }^{2}$. A large population-based, retrospective study including 2,315 primiparas and 534 multiparas concluded that episiotomy protected primiparas but not multiparas from the risk of an anal sphincter lesion; however, the indications for performing this procedure should be restricted, since 909 episiotomies would have to be performed to avoid one single case of anal sphincter rupture. ${ }^{13}$

The association found in the present study between fewer episiotomies and obstetric care provided by nurses was not surprising. In the systematic review available in the Cochrane Library, the risk of episiotomy was $20 \%$ lower in deliveries attended by midwives ( $20.7 \%$ versus $25.1 \%) .{ }^{14}$ In the present study, the risk was much smaller, since fewer than $8 \%$ of deliveries in which episiotomy was performed were attended by nurses, while almost $30 \%$ were attended by physicians.

It could perhaps be argued that episiotomy is less likely to be performed by non-physicians because these pro- fessionals only attend low-risk deliveries in which there is less need for episiotomy. Nevertheless, this explanation is not supported by the results of the present study, since a multivariate analysis was conducted and even after controlling for potentially confounding variables such as complications during pregnancy, a prolonged expulsive phase and instrumental delivery, deliveries at which episiotomy was performed were much less likely to have been attended by obstetric nurses. It is important to clarify that in the northeast of Brazil there are no university courses for midwives, which is why these professionals are not included in the childbirth care model used in this setting.

The important association between episiotomy and deliveries attended by staff physicians, but not those attended by medical residents, suggests that this procedure is strongly related to the amount of time the professional has been working in the area, since young medical residents are less likely to perform episiotomy. It is important to remember that the training of these new professionals is based on scientific evidence at a time in which the systematic practice of episiotomy in obstetrics is already being questioned. Deliveries involving episiotomy are almost twice as likely to have been attended by physician preceptors, many of whom graduated at a time in which the routine practice of episiotomy was not questioned.

As evidence accumulates on the lack of benefits of routinely performing episiotomy, we believe that young doctors will easily incorporate their critical judgment of this procedure into their clinical practice, unlike the physician preceptors who, despite the available evidence, are resistant to changes in conduct.

The association between episiotomy and forceps assisted deliveries was most evident in the present study, with a more than 12 -fold likelihood of deliveries with an episiotomy having involved the use of forceps. It should be emphasized that the use of forceps or vacuum extraction used to be considered a classic indication for episiotomy. However, in addition to there being no 
clear indication for episiotomy when an instrumental delivery is performed, the combination of an instrumental delivery and an episiotomy is believed to result in an increase in severe lacerations of the perineum, with possible damage to anal function. Recent studies recommend that this combination be avoided. ${ }^{14-16}$ Even so, many professionals continue to believe that instrumental delivery constitutes an indication for episiotomy.

Indeed, it is rather unclear in which situations episiotomy is in fact indispensable. The Cochrane systematic review raised the question regarding the real indications for this procedure: operative vaginal delivery, preterm delivery, pelvic delivery, macrosomia or the risk of severe perineal laceration. ${ }^{2}$ Consequently, a debate has ensued on whether these situations constitute indicators of a need for episiotomy and clearly require to be investigated further in new randomized clinical trials. ${ }^{17}$

With the objective of studying the factors that may affect whether or not this procedure is performed, in addition to the variables already mentioned, the present study also evaluated other factors such as pelvic presentation, prematurity, previous Cesarean section, non-reassuring heart rate, previous episiotomy, complications during pregnancy, macrosomia, induction of labor and/or the use of oxytocin during labor, and the use of analgesia during childbirth.

It was impossible to evaluate the association between episiotomy, shoulder dystocia, pelvic presentation and the diagnosis of a "risk of severe perineal laceration." Shoulder dystocia occurred in one single case and was not included as a variable in the analysis. Pelvic presentation occurred in six cases; however, there was no statistically significant association with episiotomy. On the other hand, "risk of severe perineal laceration" was not recorded on the women's medical charts as an indication for performing episiotomy, perhaps because this diagnosis is subjective. It is possible that some physicians may have performed episiotomy to protect the perineum against this risk of severe perineal laceration; however, there was no record of this indication on the medical charts. It should be emphasized that "risk of severe perineal laceration" is not an objective diagnosis and, clinically, the factors that characterize this event are not well defined. ${ }^{2,17}$

Although various authors have mentioned prematurity as an indication for episiotomy, with the objective of protecting the head of the fetus, in the present study no such association was found. Indeed, there are no clinical trials or observational studies corroborating the need for episiotomy in premature deliveries or any evidence justifying the use of episiotomy to prevent fetal trauma at delivery. ${ }^{1,2,17}$ On the contrary, a study evaluating 1,360 nulliparas submitted to forceps delivery or vacuum extraction showed that the use of episiotomy was associated with an increase in the rate of fetal contusions and skin abrasions, while having no effect on neonatal outcomes such as Apgar score, fetal acidosis or admission to a neonatal intensive care unit. ${ }^{15}$

History of a previous Cesarean section, characterizing a woman who has not yet delivered vaginally, was not associated with any increase in the risk of having an episiotomy, contrary to the findings of another study carried out in Pernambuco, Brazil..$^{18}$ On the other hand, having had a previous episiotomy was found to have a protective effect in the bivariate analysis, although this association was no longer present in the multivariate analysis.

Although the diagnosis of "non-reassuring heart rate" was associated with a greater risk of episiotomy in the bivariate analysis, this risk also failed to remain significant in the multivariate analysis. The intention of shortening the expulsive phase in cases in which anomalous fetal heart rate patterns are detected may have led some physicians to perform episiotomy. Another possible explanation is that when faced with a situation in which fetal vitality is compromised, some professionals may have opted to use forceps, and the majority of obstetricians still believe, as discussed previously, that episiotomy is fundamental when performing an instrumental delivery., 14-17

With respect to macrosomia (fetal birth weight $\geq 4$ $\mathrm{kg}$ ) no statistically significant association was found with the practice of episiotomy. This fact may have occurred as a result of the obstetricians having no information on the weight of the concept prior to delivery. It should be emphasized that it is not routine practice in this service to perform ultrasonography at term for the purpose of predicting fetal weight, since the accuracy of this exam in detecting macrosomia is poor. ${ }^{19,20}$ At any rate, studies suggest that episiotomy is not recommended either for the delivery of macrosomic fetuses or in situations in which shoulder dystocia occurs. ${ }^{17,21}$ In fact, recent evidence shows that, even in the presence of conditions classically considered as "indications" for an episiotomy (macrosomia, non-reassuring heart rate, occipito-posterior position, shoulder dystocia and instrumental delivery), the risk of third and fourth degree lacerations was significantly greater when episiotomy was performed. ${ }^{22}$

In the bivariate analysis, both analgesia at delivery and induction with oxytocin were associated with episiotomy, although this association was no longer present in the mul- 
tivariate analysis. There does not appear to be any direct association between the use of drugs to induce delivery or to provide analgesia and a need for an episiotomy; howev$\mathrm{er}$, the presence of these variables may indicate a more interventionist approach by the professional attending delivery. Induced deliveries may also be more dystocic and may trigger a cascade of other interventions ${ }^{23}$. On the other hand, some professionals may find it simpler to perform an episiotomy in patients under analgesia; however, this may also lead to an increase in the duration of the expulsive phase and a greater risk of an instrumental delivery in patients receiving epidural analgesia. ${ }^{24}$

No association was found between episiotomy and complications such as preeclampsia, hypertension, diabetes and other conditions during pregnancy that would characterize it as high-risk. We believe that the presence of these factors may increase the risk of a Cesarean section, but they do not appear to affect the clinical decision to perform an episiotomy.

In relation to the position of the woman at delivery, positions other than the supine position (upright, lateral or hands-and-knees position) were less common in the group submitted to episiotomy ( $47 \%$ versus $56 \%$ ), which is in agreement with the Cochrane systematic review suggesting that the risk of episiotomy is lower in non-supine positions. ${ }^{25}$ Nevertheless, the association between the woman's position at delivery and episiotomy did not remain statistically significant in the multivariate analysis, probably because more important factors such as the professional attending the delivery were associated both with the choice of the woman's position for delivery and with the practice of episiotomy.

The rate of episiotomy at IMIP has fallen progressively over recent years and is currently at around $10 \%$. Nevertheless, we believe that this rate can still be improved significantly, since most of the factors shown in the present study to be associated with the use of episiotomy are potentially modifiable. Stimulating care by nursing professionals at low-risk deliveries is fully possible and a measure that is recommended worldwide. ${ }^{14}$ On the other hand, we believe that all the efforts made in the institute towards forming a new generation of physicians within a paradigm of evidence-based medicine have resulted in success, with a new generation of medical residents that has incorporated the concept that routine episiotomy is unnecessary.

For the future, we would suggest broadening the discussion on the actual indications for episiotomy and questioning the true role of episiotomy in pelvic and instrumental deliveries. Some authors have suggested that episiotomy may not be absolutely necessary in childbirth. ${ }^{17,22}$
Until the results of these future clinical trials become available, we suggest that efforts be made to restrict the practice of episiotomy and maintain rates within the limits suggested by the World Health Organization, i.e. 10\% of deliveries. Both in individual and in institutional practice, it is important to document episiotomy rates and to recognize the factors associated with its practice in order to elaborate strategies to prevent unnecessary procedures that, in addition to being unwanted by women, may indeed be harmful to their health., $2,3,5-8$

\section{FUNDING}

National Council for Scientific and Technological Development (CNPq). Scientific initiation grant.

\section{Resumo}

Fatores de risco para a episiotomia: um estudo de caso-controle.

Objetivo: avaliar os fatores de risco para a episiotomia em mulheres grávidas que passaram por parto normal em uma maternidade de uma universidade no nordeste do Brasil. Métodos: um estudo de caso-controle foi realizado com gestantes submetidas à episiotomia (casos) e mulheres grávidas não submetidas à episiotomia (controles) entre março de 2009 e julho de 2010, no Instituto de Medicina Integral Fernando Figueira (IMIP), Recife, Brasil, em uma proporção de um caso para dois controles. As variáveis do estudo foram: se episiotomia foi realizada, demográficos, obstétricos e características fetais (primiparidade, analgesia, parto instrumental, sofrimento fetal, etc.), fatores externos (dia e hora do parto, profissional que realizou o parto) e fatores diretamente relacionados ao parto. Odds ratio (OR) e intervalos de confiança de $95 \%$ (IC 95\%) foram calculados. A análise multivariada foi realizada para determinar o risco ajustado de episiotomia.

Resultados: um total de 522 mulheres (173 casos e 349 controles) foi incluído. Verificou-se que os partos com episiotomia eram mais propensos a ter sido atendidos por médicos do staff (OR = 1,88, IC 95\%: 1,01 - 3,48), necessidade de fórceps (OR = 12,31, IC 95\%: 4,9 - 30,1) e ter ocorrido em primíparas ( $\mathrm{OR}=4,24,95 \% \mathrm{CI}: 2,61$ - 6,89). A probabilidade de uma enfermeira ter assistido o parto com realização de episiotomia foi significativamente menor $(\mathrm{OR}=0,29,95 \% \mathrm{CI}$ : $0,16-0,55)$.

Conclusão: a episiotomia foi considerada fortemente associada a partos assistidos por médicos da equipe, primiparidade e a parto instrumental, e foi menos comum em partos assistidos por enfermeiros. 
Palavras-chave: episiotomia, parto normal, fatores de risco, períneo/lesões, estudos de casos e controles.

\section{RefEREnCES}

1. Myers-Helfgott MG, Helfgott AW. Routine use of episiotomy in modern obstetrics. Should it be performed? Obstet Gynecol Clin North Am. 1999;26:305-25

2. Carroli G, Mignini L. Episiotomy for vaginal birth. Cochrane Database Syst Rev. 2009;(1):CD000081.

3. Eckman A, Ramanah R, Gannard E, Clement MC, Collet G, Courtois L, et al. [Evaluating a policy of restrictive episiotomy before and after practice guidelines by the French College of Obstetricians and Gynecologists]. J Gynecol Obstet Biol Reprod (Paris). 2010;39:37-42.

4. Levitt C, Hanvey L, Bartholomew S, Kaczorowski J, Chalmers B, Heaman M, et al. Maternity Experiences Study Group; Public Health Agency of Canada. Use of routine interventions in labour and birth in Canadian hospitals: comparing results of the 1993 and 2007 Canadian hospital maternity policies and practices surveys. J Obstet Gynaecol Can. 2011;33:1208-17.

5. World Health Organization. Maternal and newborn health/safe motherhood unit. Care in normal birth: a practical guide. Geneva: WHO; 1996.

6. World Health Organization. Managing complications in pregnancy and childbirth. A guide for midwives and doctors. Geneva: WHO Department of Reproductive Health and Research; 2003.

7. Faruel-Fosse H, Vendittelli F. [Can we reduce the episiotomy rate?]. J Gynecol Obstet Biol Reprod. (Paris) 2006;35(1 Suppl):1S68-1S76.

8. Goldberg J, Purfield P, Roberts N, Lupinacci P, Fagan M, Hyslop T. The Philadelphia Episiotomy Intervention Study. J Reprod Med. 2006;51:603-9.

9. Allen RE, Hanson RW Jr. Episiotomy in low-risk vaginal deliveries. J Am Board Fam Pract. 2005;18:8-12.

10. Victora CG, Huttly SR, Fuchs SC, Olinto MT. The role of conceptual frameworks in epidemiological analysis: a hierarchical approach. Int J Epidemiol. 1997;26:224-7.

11. Hueston WJ. Factors associated with the use of episiotomy during vaginal delivery. Obstet Gynecol. 1996;87:1001-5.
12. Rodriguez A, Arenas EA, Osorio AL, Mendez O, Zuleta JJ. Selective vs routine midline episiotomy for the prevention of third- or fourth-degree lacerations in nulliparous women. Am J Obstet Gynecol. 2008;198:285.e1-4.

13. Räisänen SH, Vehviläinen-Julkunen K, Gissler M, Heinonen S. Lateral episiotomy protects primiparous but not multiparous women from obstetric anal sphincter rupture. Acta Obstet Gynecol Scand. 2009;88:1365-72.

14. Hatem M, Sandall J, Devane D, Soltani H, Gates S. Midwife-led versus other models of care for childbearing women. Cochrane Database Syst Rev. 2008;(4):CD004667.

15. Macleod M, Strachan B, Bahl R, Howarth L, Goyder K, Van de Venne M, et al. A prospective cohort study of maternal and neonatal morbidity in relation to use of episiotomy at operative vaginal delivery. BJOG. 2008;115:1688-94.

16. Yeomans ER. Operative vaginal delivery. Obstet Gynecol. 2010;115:645-53

17. Amorim MMR, Katz, L. [The role of episiotomy in modern obstetrics] Femina. 2008;36:47-54

18. Carvalho CCM, Souza ASR, Moraes Filho OB. [Prevalence and factors associated with the practice of episiotomy at a maternity school in Recife, Pernambuco, Brazil]. Rev Assoc Med Bras. 2010;56:333-9.

19. Coomarasamy A, Connock M, Thornton J, Khan KS. Accuracy of ultrasound biometry in the prediction of macrosomia: a systematic quantitative review. BJOG 2005;112:1461-6

20. Colman A, Maharaj D, Hutton J, Tuohy J. Reliability of ultrasound estimation of fetal weight in term singleton pregnancies. N Z Med J. 2006;119:U2146.

21. Paris AE, Greenberg JA, Ecker JL, McElrath TF. Is an episiotomy necessary with a shoulder dystocia? Am J Obstet Gynecol.2011;205:217.e1-3.

22. Steiner N, Weintraub AY, Wiznitzer A, Sergienko R, Sheiner E. Episiotomy: the final cut? Arch Gynecol Obstet. 2012;286:1369-73.

23. Tracy SK, Sullivan E, Wang YA, Black D, Tracy M. Birth outcomes associated with interventions in labour amongst low risk women: a population-based study. Women Birth. 2007;20:41-8.

24. Anim-Somuah M, Smyth RM, Jones L. Epidural versus non-epidural or no analgesia in labour. Cochrane Database Syst Rev. 2011;(12):CD000331.

25. Gupta JK, Hofmeyer GJ, Shehmar M. Position in the second stage of labour for women without epidural anaesthesia. Cochrane Database Syst Rev. 2012;5:CD002006 